\title{
WHAT EXPLAINS HADZA FOOD SHARING?
}

\author{
Frank W. Marlowe
}

\begin{abstract}
Most hypotheses proposed to explain human food sharing address motives, yet most tests of these hypotheses have measured only the patterns offood transfer. To choose between these hypotheses we need to measure people's propensity to share. To do that, I played two games (the Ultimatum and Dictator Games) with Hadza hunter-gatherers. Despite their ubiquitous food sharing, the Hadza are less willing to share in these games than people in complex societies are. They were also less willing to share in smaller camps than larger camps. I evaluate the various food-sharing hypotheses in light of these results.
\end{abstract}

\section{INTRODUCTION}

Among mammals, when food sharing occurs at all it is usually limited to the provisioning of offspring (or mates), although wider sharing occurs among some cooperative breeders like wild dogs (Solomon \& French, 1997). Adult lions will often share a carcass but not without a lot of snarling (Packer \& Pusey, 1997). When a chimpanzee kills a colobus monkey, certain adults may get a share if they beg with outstretched hand or slowly reach for the meat (McGrew \& Feistner, 1992; Mitani \& Watts, 2000). In contrast, among human foragers (and some other types of societies), there is widespread sharing of food outside the household which does not even require begging; e.g. Hadza (Woodburn, 1998), Aka (Kitanishi, 1998),

Socioeconomic Aspects of Human Behavioral Ecology

Research in Economic Anthropology, Volume 23, 69-88

Copyright $\odot 2004$ by Elsevier Ltd.

All rights of reproduction in any form reserved

ISSN: 0190-1281/doi:10.1016/S0190-1281(04)23003-7 
Ache (Kaplan \& Hill, 1985), Hiwi (Gurven et al., 2000), Australian societies (Peterson, 1993). Here, I evaluate what motivates this food sharing using data from games I played with Hadza hunter-gatherers in Tanzania. In contrast to most studies of food sharing, which focus on the pattern of food transfers and then infer something about motives (for a review see Gurven, n.d.), my goal here is to draw attention to motivation itself.

Two games that measure sharing propensity are the ultimatum and dictator games. In the ultimatum game (UG) the first player (proposer) must decide how to divide a given amount of stakes with the second, anonymous player (responder). If the responder accepts the anonymous proposer's offer, he or she receives that amount and the proposer gets the remainder, e.g. if the stakes are $\$ 100$ and the proposer offers $\$ 10$, and the responder accepts, the responder gets $\$ 10$ and the proposer gets $\$ 90$. On the other hand, if the responder rejects the proposer's offer, both receive nothing. Thus, the responder can, at a cost to herself, punish the proposer for making a low offer. The dictator game (DG) is played exactly like the UG except that the second player cannot reject an offer. Thus, the proposer can dictate the division.

The UG elicits one's propensity to share (if proposer) or punish (if responder). The DG reveals one's willingness to share when there is no risk. Standard economic theory suggests the UG responder should accept any offer above zero, since something beats nothing. Because the proposer should figure this out, he or she should offer only one unit above zero in the UG. Zero is the expected offer in the DG. Experiments in complex societies, however, have shown that proposers offer much more. In fact, the modal UG offer is $50 \%$ and modal DG offer between 30 and $50 \%$ (Camerer \& Thaler, 1995). UG offers in complex societies seem irrationally high, unless responders reject offers above $0 \%$, and they do. Offers under $20 \%$ have about a $50 \%$ chance of being rejected (Henrich, 2000).

In addition to the Hadza, fourteen other small-scale societies played the UG in a MacArthur Foundation experimental economics project, and I occasionally refer to those results. I use these games to analyze food sharing because they provide insight into motives not always clear from the pattern of food sharing itself. By motives I mean something like individual goals, which may or may not be conscious.

\section{Explanations of Food Sharing}

Table 1 enumerates the following explanations of food sharing.

(1) Mutualism. In some contexts, there is no benefit to defecting in a cooperative venture. For example, when two or more individuals have a much greater 
Table 1. Food Sharing Explanations.

1. Mutualism (food for foraging partners)

2. Nepotism (food for kin)

3. Reciprocity

(a) Not-in-kind exchange (food A for food B)

(b) In-kind, delayed reciprocity (food now for food later)

4. Costly signaling (food for non-food benefits)

5. Tolerated scrounging (food for peace)

chance of getting some meat by attacking prey at the same time, cooperative hunting can evolve, and this might result in all hunters getting some of the spoils, as perhaps among lions (Packer \& Pusey, 1997). This does not mean that food shared following cooperative foraging is an example of mutualism, only that in such a context, it must be considered.

(2) Nepotism. Individuals should be willing to give food to kin when the cost (C) to the giver is less than the benefit (B) to the recipient, times the coefficient of relatedness ( $r)$ between giver and recipient $(\mathrm{C}<\mathrm{B} \times \mathrm{r})$ (Hamilton, 1964). Selection can favor a gene that promotes such behavior, so sharing food with close kin presents no puzzle and female mammals have evolved specialized organs (mammary glands) to do just this.

(3a) Not-in-kind Exchange. This entails the exchange (often immediate) of one type of resource for another, such as meat for berries. This must account for some of the sharing between husbands and wives who bring in different kinds of foods and then eat some of their spouse's food (Winterhalder, 1986). Not-in-kind exchange may also include food for non-food goods (or perhaps services), and may account for mate provisioning if that is the price for mating access.

(3b) In-kind, Delayed Reciprocity. When there is considerable daily variance in a foragers' food returns and little correlation in daily returns across foragers, giving food to others will pay - so long as it is reciprocated - because this will make it more likely one will get something to eat everyday (Winterhalder, 1986). The evolution of reciprocity is facilitated when individuals live in small groups, regularly interact, keep track of others' interactions, and have a high probability of future interactions (Axelrod, 1984; Trivers, 1971), all features of human foragers. However, some foragers may be more productive than others, either because they are more skilled or because they try harder, and end up giving out much more food than they receive (Hawkes et al., 1991). This makes delayed reciprocity riskier and potentially less balanced than immediate, not-in-kind exchange. 
(4) Costly Signaling. The showoff hypothesis proposed that men hunt and share meat because they are repaid with mating opportunities or other social benefits (Hawkes, 1991). If a hunter gained an extra mating by sharing his meat, and if this is why he bothered to hunt, this would be a not-in-kind exchange of goods for services. However, if a man shares his meat with all in camp, there is no incentive for any individual woman to repay him with sex if she receives meat without doing so. Costly signaling proposes a similar motivation and payoff, but avoids the collective action problem inherent in the showoff hypothesis because it argues a woman gains from mating with a good hunter if hunting is a reliable signal of his phenotypic (or genotypic) quality (Gintis et al., 2001; Hawkes \& Bliege Bird, 2002; Zahavi, 1995). Hunting may be a good test of some qualities because it is difficult, and it may be a good way to signal because sharing meat attracts a large audience (Smith \& Bliege Bird, 2000).

When we focus on motivation, costly signaling comes close to being a delayed, not-in-kind exchange of goods for services if it involves meat and sex, but it could take other forms. For example, hunting success may signal a man's fighting ability, which might cause other males to defer to him in disputes. Deference is more difficult to construe as a service. Here, I deal only with signaling of phenotypic quality relevant to potential mates because it is the most explicit and therefore testable scenario offered for how costly signaling could work. Because costly signaling is meant to be about communication and quite distinct from not-in-kind exchange, it could just as well take the form of a forager acquiring lots of food and then, in front of his audience, destroying it all rather than sharing it. Therefore, costly signaling is not really an explanation of sharing per se but an explanation of why foragers might be motivated to engage in costly behaviors. Those costly behaviors might involve acquiring much food, which is then given away.

(5) Tolerated Scrounging. With large packages of food, each additional unit consumed will have diminishing marginal utility for the owner and greater value for those who have not yet eaten, who should be more willing to contest those units. If the cost of defending additional units is greater than the benefit, it pays to share them (Blurton Jones, 1984, 1987; Isaac, 1978). Once scrounging occurs, production becomes a game of chicken (Hawkes, 1992), resulting in a mixed producer/scrounger strategy (Vickery et al., 1991) and depressed production. Foods acquired with considerable daily variance are more vulnerable to scrounging (Winterhalder, 1996), but they are also the ones most likely to be exchanged in delayed reciprocity, making it difficult to test between these two hypotheses based on the types of food distributed (Bliege-Bird \& Bird, 1997; Kaplan \& Hill, 1985). 


\section{Motive vs. Pattern of Food Transfers}

It is important to distinguish between the food giver's desire to share, which I will call motive, and the observed pattern of food transfers. Sometimes they coincide, sometimes not. If the motivation for taking food back to camp is to feed one's siblings or children (which of course may be a conscious goal) in order to enhance inclusive fitness via nepotistic provisioning (not a conscious goal), and food is given only to close kin, then the motive explains the pattern of food transfer and vice versa. However, suppose one takes food back to camp to feed one's children, but once in camp others expect and receive shares. Then, although the motive was nepotism, the transfer is explained by reciprocity or scrounging.

Of the six food sharing explanations in Table 2, only four imply the food giver wants to give out food, two entail no desire to give (noted by a). Tolerated scrounging explains only why others get shares regardless of the wishes of the giver, and mutualism results in sharing only as an incidental by-product of synchronized foraging. On the other hand, costly signaling is mostly an explanation of motive, not an explanation of the particular pattern of food transfers. For example, tolerated scrounging might explain why everyone gets some of the hunter's meat, while costly signaling is invoked only to explain why the hunter bothers to hunt. Costly signaling can be distinguished from the two types of reciprocity, but like them it implies the food giver has a motive, and that motive is to receive some benefit in return for foraging effort whatever the reason people are willing to confer the benefit.

The food-sharing hypotheses are more distinct with regard to motivation for sharing than they are with regard to predicted pattern of food transfers, yet there has been little or no investigation of the motivation and decision-making involved. Measuring only the pattern of food transfers is akin to noting only the mates people have, not who they would prefer to have. Without data on mate preferences, we might erroneously assume that people are with their ideal mates. Likewise, without data on sharing preferences unconstrained by external pressures, we might erroneously conclude that food givers want to give away the amount of food they do to the people they do.

\section{Types of Food Sharing}

Food is shared in various contexts and all of the hypotheses above likely account for some of the sharing observed in different circumstances. For example, mutualism might or might not account for the sharing of food between two foragers who eat what they acquire on the spot, but cannot account for the sharing that occurs when a forager takes food back to camp. Just as in complex societies, much forager food 
Table 2. Motivation, Pattern of Transfers, and Game Predictions From Hypotheses.

\begin{tabular}{|c|c|c|c|}
\hline Food Sharing Hypothesis & Giver's Motive & Food Recipients & Game Predictions \\
\hline Mutualism & $\begin{array}{l}\text { Increase own } \\
\text { foraging returns } \mathrm{s}^{\mathrm{a}}\end{array}$ & Co-foragers & Not tested \\
\hline Nepotism & $\begin{array}{l}\text { Raise inclusive } \\
\text { fitness }\end{array}$ & Close kin ${ }^{\mathrm{b}}$ & Not tested \\
\hline \multicolumn{4}{|l|}{ Reciprocity } \\
\hline Not-in-kind exchange & $\begin{array}{l}\text { Optimize diet } \\
\text { breadth }\end{array}$ & $\begin{array}{l}\text { One with different } \\
\text { foods }{ }^{b}\end{array}$ & Not tested \\
\hline In-kind delayed reciprocity & $\begin{array}{l}\text { Reduce daily } \\
\text { variance in food } \\
\text { consumption }\end{array}$ & $\begin{array}{l}\text { Sharing partners, } \\
\text { especially successful } \\
\text { foragers }^{\mathrm{b}}\end{array}$ & $\begin{array}{l}\text { (1) High UG/DG } \\
\text { offers }(50 \%)^{\mathrm{c}} \\
\text { (2) UG/DG offers }< \\
\text { in larger camps }{ }^{\mathrm{c}} \\
\text { (3) High rejection of } \\
\text { low UG offers }\end{array}$ \\
\hline Costly signaling & Gain mates, allies & $\begin{array}{l}\text { Fertile females and } \\
\text { worthy allies }{ }^{\mathrm{b}}\end{array}$ & $\begin{array}{l}\text { (4) High UG/DG } \\
\text { offers }(=50 \%)^{\mathrm{c}} \\
\text { (5) Male UG/DG } \\
\text { offers }>\text { Female } \\
\text { (6) UG/DG offers > } \\
\text { in larger camps }{ }^{\mathrm{d}}\end{array}$ \\
\hline Tolerated scrounging & Avoid contest ${ }^{\mathrm{a}}$ & $\begin{array}{l}\text { All present, or at } \\
\text { least all with } \\
\text { leverage }\end{array}$ & 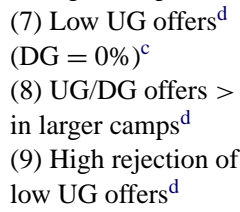 \\
\hline
\end{tabular}

${ }^{\mathrm{a}}$ Food giver has no desire to give.

${ }^{\mathrm{b}}$ Recipients are intended recipients.

${ }^{\mathrm{c}}$ Hypothesis is supported.

${ }^{\mathrm{d}}$ Hypothesis not supported.

sharing occurs within households, but there is also considerable sharing outside the household, often with everyone in camp, thus nepotism is a poor explanation (see Jones (2000), however, for an explanation of group nepotism). Finally, not-in-kind food exchange occurs among foragers, especially between husband and wife, with men specializing in hunting and women in gathering, but does not seem to explain why good hunters are so often supplying others with meat. Because not-in-kind exchange can explain why husbands and wives share different kinds of food, nepotism appears to explain sharing with children, and mutualism cannot explain the sharing of food taken back to camp, I exclude those hypotheses. Instead, here I am interested 
in explaining the widespread sharing of food across households in camp. Therefore, I focus only on the three hypotheses most relevant to this type of food sharing: (a) delayed, in-kind reciprocity; (b) costly signaling; and (c) tolerated scrounging.

\section{Game Predictions}

If we assume players' decisions in the ultimatum and dictator games are guided by predispositions they have when sharing food, we can make the following nine predictions from the three different food-sharing hypotheses (see Table 2).

For delayed, in-kind reciprocity to work well, there needs to be a contingent, somewhat balanced flow of food, at least in terms of utility (Winterhalder, 1996). Individuals also need a strong commitment to fairness; without it, free riding would erode the incentive to produce. The best strategy to promote in-kind reciprocity is the so-called tit-for-tat strategy of cooperate until defected upon. Sharing equally with one's partners is a good way to signal that one is cooperating, so if delayed, in-kind reciprocity accounts for food sharing, we should expect a stronger commitment to fairness in a society where there is extensive food sharing than in a society where there is less extensive food sharing. Therefore, we can predict that (1) subjects like the Hadza will make high UG and DG offers. By high, I mean at least as high as offers in complex societies where there is less food sharing. Delayed reciprocity requires detecting cheaters to avoid cooperating with them in the future, and because this becomes more difficult as population increases, free-riders should increase and undermine delayed reciprocity in large groups (Boyd \& Richerson, 1988). We can therefore predict that (2) subjects living in larger camps should make lower UG and DG offers. Punishment can maintain delayed reciprocity, and even though it is a public good upon which others can free-ride, we might expect moralistic aggression toward cheaters (Fehr \& Gachter, 2002; Trivers, 1971) and predict that (3) low UG offers will be rejected at high rates (at least as high as in complex societies).

Costly signaling implies foragers want to share their food as a means of advertising their phenotypic quality. Therefore, we can predict that (4) subjects will make high UG and DG offers, perhaps $50 \%$ or even greater. If advertising one's quality leads to more frequent mating opportunities (or better allies), men might stand to gain more than women do from advertising. Therefore, if it is hunting success that is the signal, we can predict that (5) men will make higher UG and DG offers than women (though not if both sexes gain equally from signaling generosity to gain "social benefits"). Because there are more potential mates or allies to advertise to and more benefits to be had in larger groups, we can predict that (6) subjects will make higher UG and DG offers in larger camps. 
Tolerated scrounging implies the food giver does not really want to give food, therefore we can predict that (7) subjects will make the lowest possible UG offers that do not provoke rejection (income maximizing offers), and give $0 \%$ in the DG. The relative dominance of individuals might influence tolerated scrounging. For example, a female leopard sometimes loses her prey to a male leopard, until he is sated. If weaker individuals gang-up on the stronger however, dominance should matter less and the number of scroungers more. For example, a pack of hyenas often steals prey from a leopard, and so do the Hadza. This is theft, pure and simple, which occurs more between groups while tolerated scrounging occurs more within groups. Because the number of potential scroungers and pressure to share is greater in larger groups, we can predict that (8) subjects will be inclined to make higher UG and DG offers in larger camps. Finally, because tolerated scrounging is based on others claiming shares (perhaps equal shares) and their feeling of entitlement is what drives sharing, we can predict that (9) low UG offers will be rejected at high rates.

Anonymity in the games means there is no way a proposer's offer can be reciprocated, nor is there an audience to signal or advertise to, nor is there anyone applying scrounging pressure. Thus, the games alter the conditions of real food sharing. This is a drawback since one might argue that, without one's identity being known, there is no reason for one to advertise. However, the anonymity is also an advantage since it allows us to see more clearly what people will do when they are free to decide. For the predictions to make sense, we need only assume that game decisions are guided by something like an impulse or a norm that is internalized, which is the product of daily life in a particular society. For example, we might find that people in a society with competitive feasting and gift-giving make very high offers, despite anonymity. We might also expect these games to elicit fair offers from those who believe strongly in fairness, which appears to be the case in complex societies, where $50 \%$ is the most common offer even when partners are anonymous.

\section{Hadza Foraging and Sharing}

The Hadza are mobile, egalitarian hunter-gatherers who live in a savanna-woodland habitat in northern Tanzania and number about 1000 (Blurton Jones et al., 1992). They live in camps that are flexible in composition with an average population of 29 (10-130), and move about every 1-2 months in response to several factors, such as availability of water and berries. The Hadza are not territorial and people are free to move wherever they please, though a core group of people tends to rotate through the same sites. Large camps are noticeably different from small camps. There is more segregation by sex in large camps with men sitting together in the 


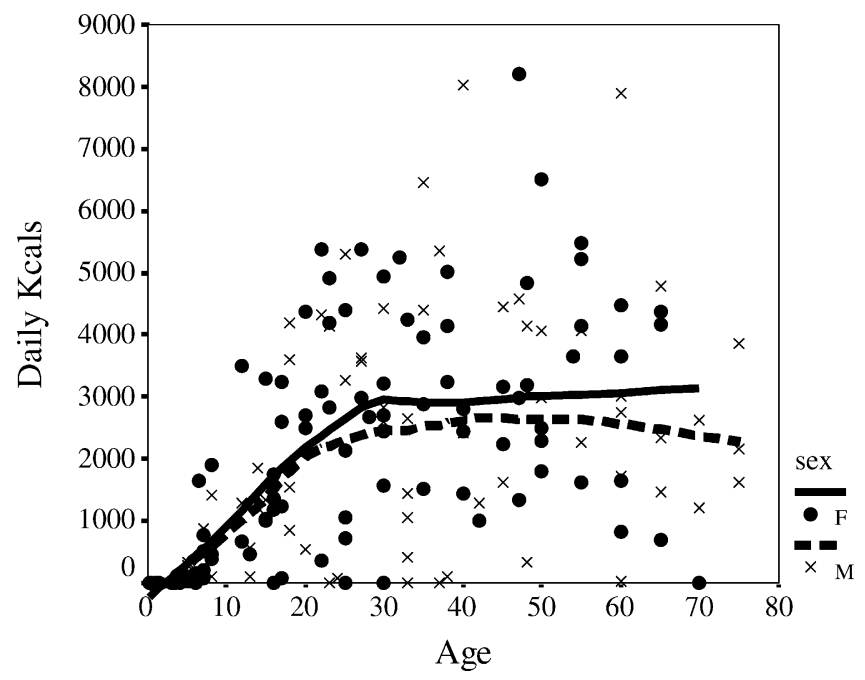

Fig. 1. Daily Kilocalories Brought Into Camp by Hadza Males and Females By Age. Note: Regression lines are lowess smooth.

men's place under the best shade tree, and women together under the second best shade tree. As the Hadza often note, there is a lot more bickering in large camps. I also found that men provide less direct care to their biological children in larger camps (Marlowe, 1999).

Based on my data collected on 187 people in five camps over 10 months in $1995 / 1996$, Hadza men $(n=51)$ forage 5.7 hours and women $(n=59) 4.2$ hours per day. Hadza women dig tubers and gather fruit while men mostly hunt mammals and birds and collect honey and fruit. Hadza females acquire $60 \%$ and males $40 \%$ of daily kilocalories (kcal) brought into camp, but among adults, it is 55 and $45 \%$ respectively (Fig. 1). Among couples with a nursing infant however, husbands contribute $69 \%$ and their wives $31 \%$ of daily kcals (Marlowe, 2003). These data only include the food that is brought back to camp, not the roughly $30 \%$ that is consumed while out foraging.

Unless men find a lot of honey, which accounts for much of men's food (Table 3), they may eat all they find and take no honey back to camp, and such production is missing from these data. Men also eat some small game on the spot but medium sized game, like gazelle, is carried back to camp. When men kill very large game, like buffalo or giraffe, they sometimes take as much as they can carry back to camp, then others go to the kill site and butcher and carry back their own portions. Sharing of very large game in such cases then consists of merely telling others 
Table 3. Percentages of Total Diet (in Kilocalories by Food Type) Brought Into Camp by Adult Men and Women, and People of all Ages.

\begin{tabular}{lrrrrrrr}
\hline Food Acquired by & $\begin{array}{c}\text { Berries } \\
(\%)\end{array}$ & $\begin{array}{c}\text { Tubers } \\
(\%)\end{array}$ & $\begin{array}{c}\text { Honey } \\
(\%)\end{array}$ & $\begin{array}{c}\text { Baobab } \\
(\%)\end{array}$ & $\begin{array}{c}\text { Meat } \\
(\%)\end{array}$ & $\begin{array}{r}\text { Maize/Millet } \\
(\%)\end{array}$ & $\begin{array}{c}\text { Total } \\
(\%)\end{array}$ \\
\hline Both sexes (all ages) & 17.2 & 23.5 & 14.2 & 19.2 & 19.3 & 6.6 & 100 \\
Women ( $\geq 18$ years old) & 24.8 & 38.8 & 0.7 & 25.6 & 1.2 & 8.9 & 100 \\
Men $(\geq 18$ years old $)$ & 6.3 & 5.0 & 30.2 & 13.8 & 39.6 & 5.1 & 100 \\
\hline
\end{tabular}

where the carcass is. Men usually hunt alone. During the late dry season however, they often hunt at night, waiting in ambush at waterholes, always in pairs because large carnivores that use the same strategy pose a danger. After an animal is shot, men often return to camp and wait for the poison to kill the animal. Then, other men go with them to follow the blood trail and tracks. Men's foods, such as meat and honey, that do make it back to camp do so with greater variance and tend to be shared more widely outside the household than women's foods (Table 3).

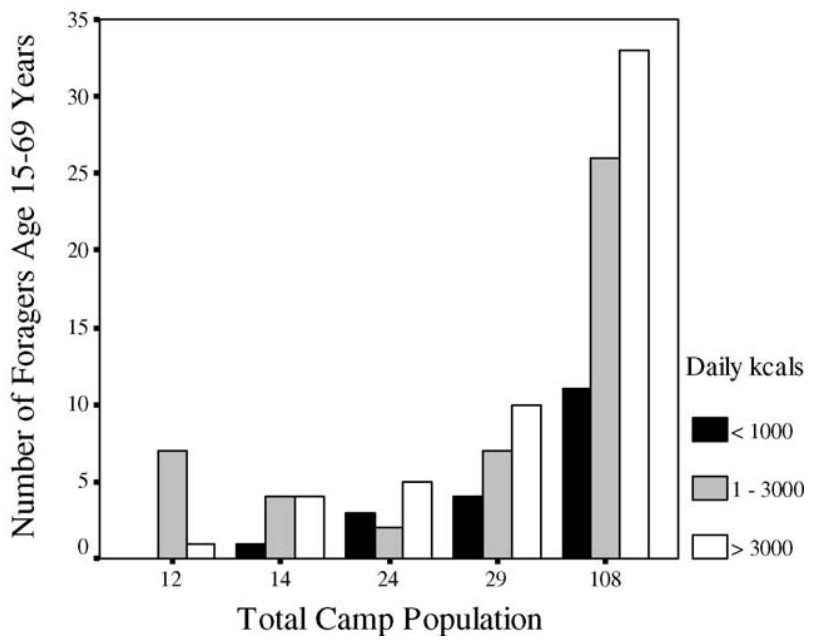

Fig. 2. Adult Hadza Producers, Scroungers, and Super-Producers by Camp Population. Note: Number of foragers (age 15-69 years old) who brought different amounts of daily kilocalories of food into camp by total population of camp. Adults who brought in $<1000$ daily kcal (scroungers) were likely being subsidized by producers (1-3000 daily kcal) and super-producers ( $>3000$ daily $\mathrm{kcal}$ ). Note the absolute number of scroungers (free-riders) increases with population, which might partly explain the greater amount of bickering in large camps. 
When women dig for tubers, they go in groups of 3-10. They sometimes cooperate by helping each other lever boulders up to get at tubers, and usually roast and eat some before returning to camp with the bulk of their haul. When picking berries, women will eat many but will also fill up baskets and take them back, whereas men and children tend to eat all they pick. We can therefore infer that women share berries more than men or children, and not all of this sharing is within the household. During the berry season, the bulk of the diet is berries, and since most are eaten while foraging, they surely comprise a greater percent of the total diet consumed than the 17\% shown in Table 3. Hadza children forage for themselves from a very early age, and are able to meet about half their needs by the time they are 10 (Blurton Jones et al., 1989; Hawkes et al., 1995), but take back to camp a lower percentage of what they acquire than adults do.

If we assume people who bring in less than 1000 daily kcal are more often receiving food from others, we can see that the absolute number (not the percent) of adult scroungers increases with population (Fig. 2), supporting the prediction that free riders should increase with group size. A few individuals in this sample were disabled or very old and did not forage at all (the very old are excluded in Fig. 2 since age is $<70$ years). The camps with 24 and 29 people had the highest percentage of adults who were being subsidized by close kin. Nepotistic provisioning is one obvious motive for taking food back to camp, while another is provisioning,

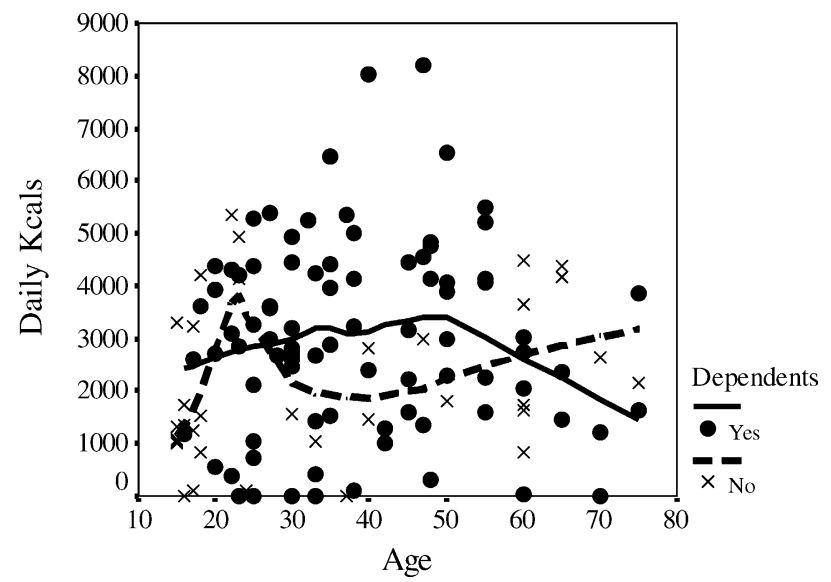

Fig. 3. Daily Kilocalories of Food Brought Into Camp by Adult Hadza by Age. Note: Status of those with and without dependents: $\times$ 's and dashed line $=$ not married and have no biological child $\leq 8$ years old at home; squares and solid line $=$ married and/or have at least one biological child $\leq 8$ years old at home (statistics are for a multiple linear regression, controlling for age; regression lines are lowess smooth). 
or trading with, a mate. Controlling for age, people who had a biological child $\leq 8$ years old at home, and/or were married, took back to camp significantly more daily kilocalories of food than did single people without young biological children at home (Fig. 3). Some young, singles (males and females) do bring in many daily kcals (note the 20 year-olds in Fig. 3), perhaps because having a reputation as a good forager helps one acquire a better mate. "Good forager" is frequently cited by males and females as an important trait in a potential mate (Marlowe, 2004a) and there appears to be assortative mating with respect to foraging returns (Hawkes et al., 2001a).

\section{METHODS}

I played the UG and DG with most adults in five camps ranging in population from 16 to 134 . In both games, players were anonymous and were randomly paired with other Hadza within the camp. The Hadza are fluent in Swahili as a second language and I conducted the games in Swahili with one person at a time inside a Land Rover with stakes laid out in front of the player who sat across from me. The stakes in the UG were 2000 Tanzania shillings (US\$3.08), about a day's wage in Tanzania. Because the Hadza are not very familiar with numbers, I used ten 200 shillings bills, which they could move around to make it easier for them to add and subtract. I first quizzed participants and scored their comprehension by how many examples it took them to get correct answers with imaginary UG offers. In the DG, instead of money I used 10 containers of beads of about the same value. For more detail on methods see (Marlowe, 2004b).

\section{RESULTS}

\section{The Ultimatum Game}

There were 55 pairs of players, 55 males ( 27 proposers, 28 responders) and 55 females ( 28 proposers, 27 responders), mean age $=37$ years (range 17-70 years). In contrast to the modal offer of $50 \%$ that is typical of industrialized societies (Camerer \& Thaler, 1995), the Hadza modal offer was 20\% (median $=30 \%$, $\mathrm{SD}=17, n=55$ ) (Fig. 4). Hadza offers were significantly lower than U.S. offers among Los Angeles graduate students (Henrich, 2000) (Mann-Whitney $U=174$, $p<0.0005, n=70$ ).

Hadza proposers earned significantly more than responders did (47\% vs. $29 \%$, $t=3.61, p<0.0005, \mathrm{df}=98.2$, unequal variances). However, the Hadza rejected 


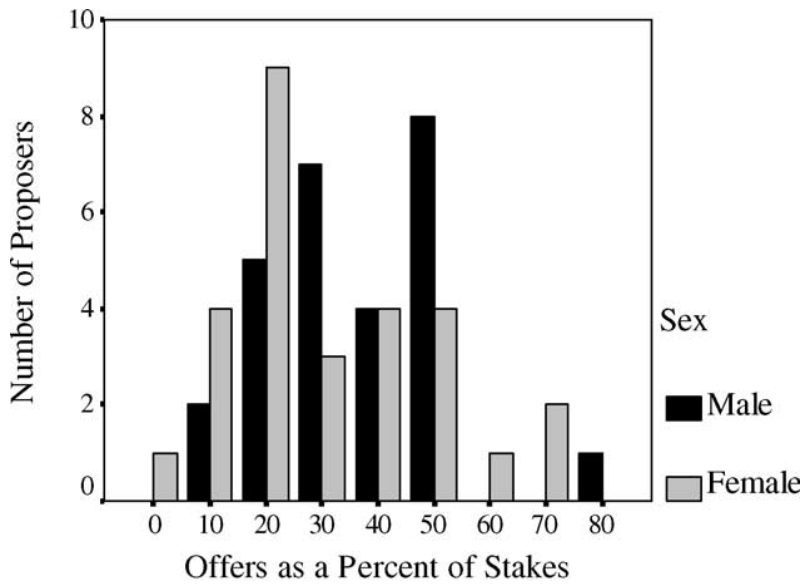

Fig. 4. Number of Hadza Proposers Making Various Offers in the Ultimatum Game.

$24 \%$ of all offers (mean offer rejected $=18 \%, 0-40 \%$ ). Thus, like people in complex societies, they were quite willing to reject. For example, $39 \%$ of all offers $\leq 30 \%$ were rejected. The maximum possible overall earnings equal $50 \%$ per person when there are no rejections and group benefit is maximized, but because Hadza offers were low and rejections high, their overall earnings were low $($ mean $=38.1 \%, \mathrm{SD}=27.5$, range $=0-90 \%, n=110$ ).

In a multiple linear regression analysis of age, sex, number of children, number of siblings, comprehension, and camp population size, the only significant predictor of offers was camp population size (Table 4). Offers were higher in larger camps $(\beta=0.475, p<0.0005, \mathrm{df}=48)$ (Fig. 5). When the one largest camp is excluded, Hadza offers are much lower and not bimodal (mode $=20 \%$, median $=20 \%$,

Table 4. Ultimatum and Dictator Game Multiple Regression Results.

\begin{tabular}{lccccc}
\hline $\begin{array}{l}\text { Variables (Relationship } \\
\text { to Proposer's Offers) }\end{array}$ & \multicolumn{2}{c}{ Ultimatum (Money as Stakes) } & & \multicolumn{2}{c}{ Dictator (Beads as Stakes) } \\
\cline { 2 - 3 } \cline { 5 - 6 } & $\beta$ & & & $\beta$ & $p$ \\
\hline Age & -0.097 & 0.562 & & -0.017 & 0.926 \\
Sex $(m=1 ; f=2)$ & -0.174 & 0.199 & & -0.203 & 0.153 \\
Comprehension & 0.277 & 0.067 & & & \\
Number of siblings & 0.010 & 0.943 & & -0.196 & 0.162 \\
Number of children & -0.077 & 0.634 & & 0.040 & 0.824 \\
Camp population size & 0.475 & $<0.0005$ & & 0.544 & $<0.0005$ \\
\hline
\end{tabular}




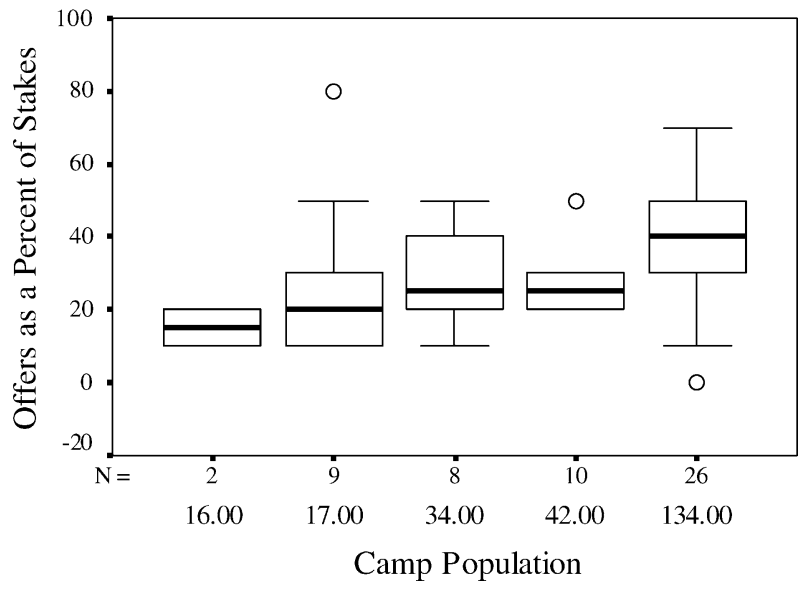

Fig. 5. Hadza Ultimatum Game Offers by Camp Population Size. Note: $B=0.475, p<$ $0.0005, \mathrm{df}=48$.

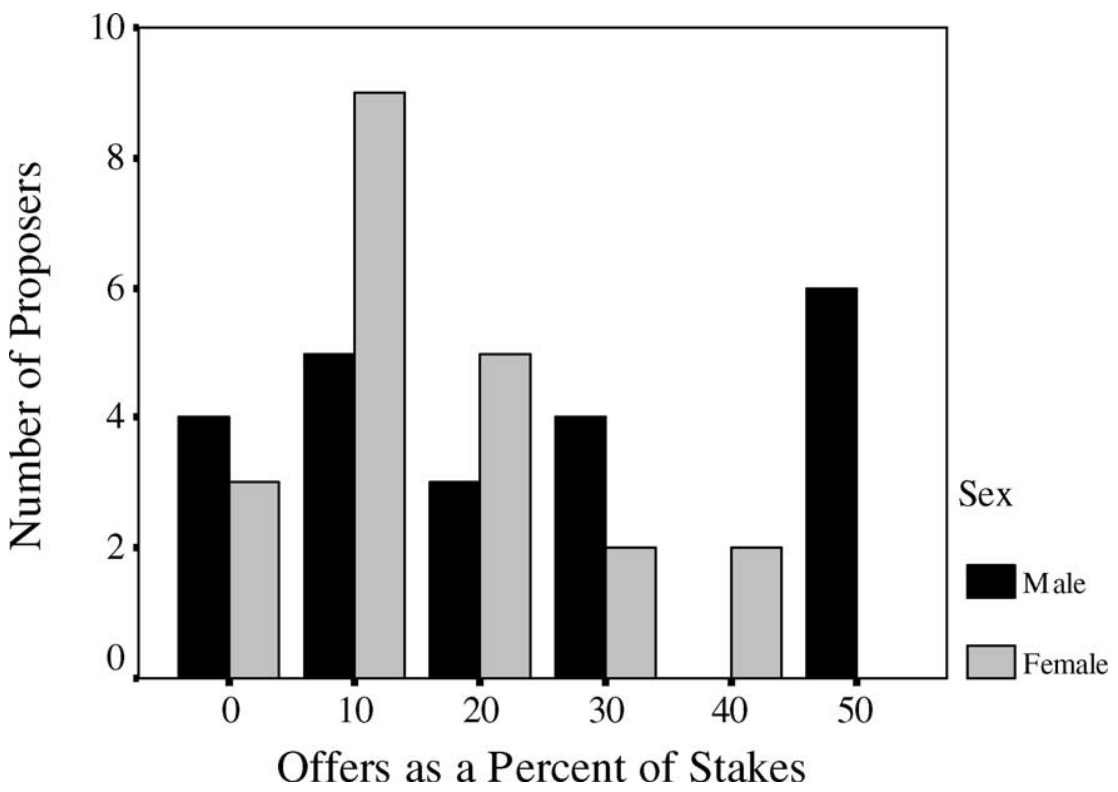

Fig. 6. Number of Hadza Proposers Making Various Offers in the Dictator Game. Note: Mode $=10 \%$, Median $=20 \%, \mathrm{SD}=16 \%, n=43$. 


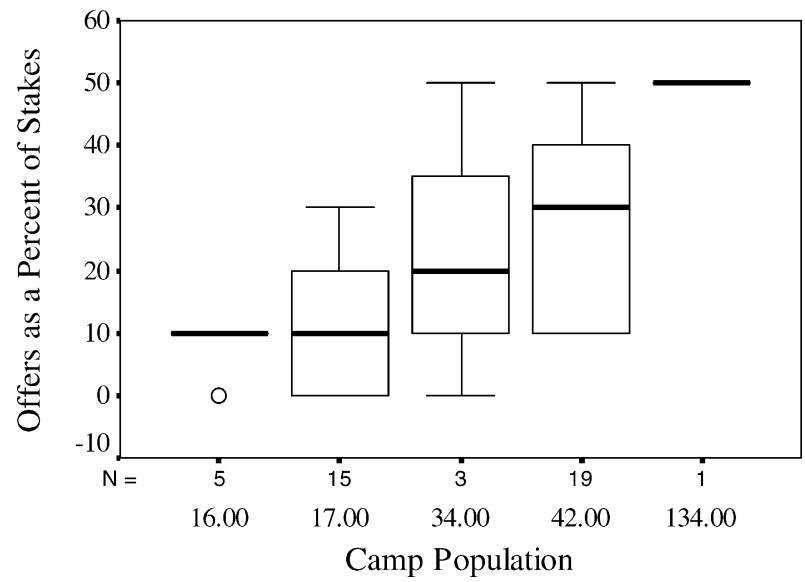

Fig. 7. Hadza Dictator Game Offers by Camp Population Size. Note: $B=0.544, p<$ $0.0005, \mathrm{df}=34$.

$\mathrm{SD}=15.6, n=29$ ), which is probably a better reflection of Hadza norms given that the largest camp was unusually large. Comprehension was not correlated with camp population size and neither was the rejection rate. However, offers of $\leq 20 \%$ were more often rejected in the largest camp than the other smaller camps $(80 \%$ or $4 / 5$ vs. $30 \%$ or $5 / 16$ ), which might explain the higher offers in the largest camp in the UG.

When asked why they made the offers they did, eight of the nine people who made offers of $50 \%$ said something like, "Giving half, or splitting it equally, is good," while four of the fifteen who made offers $\leq 20 \%$ said something like, "I wanted to keep a lot of the money." Many could not explain why they decided to give so little but some came up with a variety of rationalizations like, "I'm older," or "My partner is my friend and will understand."

\section{The Dictator Game}

In contrast to the DG modal offer of $30-50 \%$ in complex societies (Camerer $\&$ Thaler, 1995), the modal offer for the Hadza was $10 \%$ (median $=20 \%$, $\mathrm{SD}=16.2 \%, n=43$ ) (Fig. 6). In a multiple linear regression analysis of age, sex, number of children, number of siblings, and camp population size, the only significant predictor of offers was again camp population size $(\beta=0.544$, $p<0.0005$, df = 34) (Fig. 7). 


\section{DISCUSSION}

Tolerated scrounging is the hypothesis best supported by the game results here (Table 2). The only support for delayed reciprocity was the high rejection rate of low UG offers. The only support for costly signaling was the higher offers in larger camps. Most of the predictions of tolerated scrounging were supported. As predicted, offers were low by comparison to complex societies, offers were higher in larger camps, and there was a high rejection rate of low UG offers. On the other hand, DG offers were not zero percent as predicted by tolerated scrounging. This suggests that most proposers felt some impulse to be generous.

When I tell people about these games, they usually guess that the Hadza, or any foragers who regularly share food extensively, would make more generous UG and DG offers than people would in complex societies. Why do they think this? Presumably, because they assume it is generosity that motivates food sharing and that these games will elicit this. One would be hard-pressed to find a society with more extensive food sharing than the Hadza, yet they made lower offers in both games than people in complex societies. In both games, the modal offer was only one unit (10\%) higher than expected from standard economic theory, while the modal offers in complex societies are typically $40 \%$ higher. Given the probability of rejection, Hadza UG proposers came closer to maximizing their expected earnings and were much more risk-neutral than proposers in any other society tested in the MacArthur project or in complex societies (Marlowe, 2004b). Considering the Hadza can only be described as having a strong sharing ethic (which is reflected in their high rejection rate), it appears the ethic applies more to others than to oneself.

The Hadza expect a fair share of what others have. In real life, unlike the UG, this expectation is rational since the Hadza rarely face a one-shot decision but can instead keep pressure on until someone hands over a fair share. Among the Hadza, no begging or threatening is required to get food from others. The mere sight of someone's food seems to suffice, though this applies to some foods more than others. No one would think a man stingy if he shared a small bird only with his children, but large game could never be kept within the household. Although there are no precise and formal rules about division (except for certain pieces called epeme meat, that can only be eaten by men), large game is pretty equally distributed to everyone in camp, with only slightly more going to the hunter in the case of the largest game animals (Hawkes et al., 2001b).

A common misconception is that meat is shared because it will spoil and be worth nothing to the hunter anyway. However, the Hadza often eat very rotten, week-old meat they scavenge from carnivores. In addition, the Hadza (and many other foragers) know how to preserve meat by drying it. They rarely do so because it is eaten in short order. Even large animals, like giraffes, usually do not last more 
than a week because word spreads (sometimes despite efforts to keep it a secret) and people come from other camps to acquire shares. Fully $27.2 \%$ of the meat consumed in 1995/1996 came from camps other than the one within which the consumer was residing.

Hadza men have tried to hide meat inside my Land Rover, hoping to increase their chances of having an affair in the camp we were going to visit. However, try as they might, they failed because it is too difficult to hide meat and they eventually had to give it away to everyone present. Honey is also shared outside the household, but because it can be carried in a small gourd, a man can sometimes sneak it into his hut. Once a man hid his honey under my Land Rover all afternoon, in hopes of sneaking it into his house to share with his family but when he finally retrieved it, others saw it and he shared it with everyone. On the other hand, I have seen a man in a large camp successfully sneak honey into his house where he shared it with his wife, child, and two teenage girls.

Hadza say that people who do not share are bad people and that they will move away from them. Being accused of stinginess in a large group could be more dangerous than being accused by one or two people in a small group, which might explain why people felt compelled to make higher offers in large camps. Punishment is a public-good upon which others can free ride, as illustrated by rejection rates in the ultimatum game. Players are motivated to make higher offers in the game because a few will punish - one Hadza rejected an offer of $40 \%$, and several rejected $30 \%$. Other responders accepted lower offers and made more money than the spiteful punishers made. Even though offers were anonymous, perhaps the Hadza have a greater fear of punishment in larger camps with their greater bickering. The higher percent of rejections of low offers $(\leq 20 \%)$ in the largest camp suggests this fear may be well founded.

In small camps, where there may be only three or four households, all eat together and all types of food are often shared with everyone present. In the smallest camps, there is absolutely no privacy and no chance of sneaking food in, and it is interesting that in the very smallest camp in Fig. 2 there were no free-riders. In a large camp there may be 20-30 households and at times, everyone may be sitting on one side of the camp, which means that someone can more easily sneak food into their hut on the other side of camp. In large camps, people will occasionally wait until dark to return and then discreetly signal me to come weigh their food before sneaking it into their huts.

Central place foraging increases the opportunity for scrounging because anyone who returns to camp with food is likely to encounter others who are in camp without food at the time. If tolerated scrounging explains the pattern of campwide food transfers, we must ask why people take food back to camp. Household provisioning, as Fig. 3 suggests, is probably the primary motivation, especially 
for females who have weaned toddlers who are too difficult to take foraging. Under circumstances when food distribution can be controlled, for example, when someone sneaks food in, my impression is that it is given preferentially to close kin and mates. Males may acquire the foods most subject to scrounging in order to signal their quality, especially when young and trying to establish reputations. However, once they have children, even males often appear to want to direct food to their households but simply lose much of their food to scrounging.

My impression is that costly signaling, delayed reciprocity, and tolerated scrounging all play some role in explaining food sharing across Hadza households. The game results, however, are most consistent with tolerated scrounging. In evolutionary perspective, the way the Hadza played these games makes sense; they wanted to keep a larger share for themselves, yet wanted others to give them an equal share. The Hadza do not steal anything from other people, only from other species (I have avoided the term tolerated theft because it is too easily misunderstood as outright theft). When it comes to food, one does not need to steal because it simply must be shared with anyone who sees it. The Hadza share their food on a daily basis with many others while we in complex societies do not. Only when one experiences such constant demands to share can one fully appreciate how strong the desire can be to escape it.

\section{ACKNOWLEDGMENTS}

I wish to thank the Tanzanian Commission for Science and Technology for permission to conduct this research, the Hanbygotts for invaluable assistance, Nicholas Blurton Jones, Peter Gray, and Mike Alvard for comments on the manuscript, the MacArthur Foundation for funding, and the Hadza for their boundless tolerance and hospitality.

\section{REFERENCES}

Axelrod, R. (1984). The evolution of cooperation. New York: Basic.

Bliege-Bird, R., \& Bird, D. (1997). Delayed reciprocity and tolerated theft: The behavioral ecology of food-sharing strategies. Current Anthropology, 38, 49-78.

Blurton Jones, N. (1984). Selfish origin for human food sharing: Tolerated theft. Ethology and Sociobiology, 5, 1-3.

Blurton Jones, N. (1987). Tolerated theft: Suggestions about the ecology and evolution of sharing, hoarding, and scrounging. Social Science Information, 26, 31-54. 
Blurton Jones, N., Hawkes, K., \& O'Connell, J. (1989). Modelling and measuring costs of children in two foraging societies. In: V. Standen \& R. Foley (Eds), Comparative Socioecology: The Behavioural Ecology of Humans and Other Mammals (pp. 367-390). London: Blackwell.

Blurton Jones, N., O'Connell, J., Hawkes, K., Kamuzora, C., \& Smith, L. (1992). Demography of the Hadza, an increasing and high density population of savanna foragers. American Journal of Physical Anthropology, 89, 159-181.

Boyd, R., \& Richerson, P. (1988). The evolution of reciprocity in sizeable groups. Journal of Theoretical Biology, 132, 337-356.

Camerer, C., \& Thaler, R. (1995). Anomalies: Dictators, ultimatums, and manners. Journal of Economic Perspectives, 9, 209-219.

Fehr, E., \& Gachter, S. (2002). Altruistic punishment in humans. Nature, 415, 137-140.

Gintis, H., Smith, E., \& Bowles, S. (2001). Costly signaling and cooperation. Journal of Theoretical Biology, 213, 103-119.

Gurven, M. (n.d.). To give and to give not: The behavioral ecology of human food transfers. Behavioral and Brain Sciences (in press).

Gurven, M., Hill, K., Kaplan, H., Hurtado, A., \& Lyles, R. (2000). Food transfers among Hiwi foragers of Venezuela: Tests of reciprocity. Human Ecology, 28, 171-218.

Hamilton, W. (1964). The genetical evolution of social behavior. Journal of Theoretical Biology, 7 , $1-16$.

Hawkes, K. (1991). Showing off: Tests of an hypothesis about men's foraging goals. Ethology and Sociobiology, 12, 29-54.

Hawkes, K. (1992). Sharing and collective action. In: E. Smith \& B. Winterhalder (Eds), Evolutionary Ecology and Human Behavior (pp. 269-300). New York: Aldine de Gruyter.

Hawkes, K., \& Bliege Bird, R. (2002). Showing off, handicap signaling, and the evolution of men's work. Evolutionary Anthropology, 11, 58-67.

Hawkes, K., Blurton Jones, N., \& O'Connell, J. (1995). Hadza children's foraging: Juvenile dependency, social arrangements, and mobility among hunter-gatherers. Current Anthropology, 36, 688-700.

Hawkes, K., O'Connell, J., \& Blurton Jones, N. (1991). Hunting income patterns among the Hadza: Big game, common goods, foraging goals and evolution of the human diet. Philosophical Transactions of the Royal Society of London, B334, 243-251.

Hawkes, K., O'Connell, J., \& Blurton Jones, N. (2001a). Hunting and nuclear families: Some lessons from the Hadza about men's work. Current Anthropology, 42, 681-709.

Hawkes, K., O'Connell, J. F., \& Blurton Jones, N. (2001b). Hadza meat sharing. Evolution and Human Behavior, 22, 113-142.

Henrich, J. (2000). Does culture matter in economic behavior? Ultimatum game bargaining among the Machiguenga Indians of the Peruvian Amazon. American Economic Review, 90, 973-979.

Isaac, G. (1978). The food-sharing behavior of protohuman hominids. Scientific American, 238, 90-108.

Jones, D. (2000). Group nepotism and human kinship. Current Anthropology, 41, 779-809.

Kaplan, H., \& Hill, K. (1985). Food sharing among Ache foragers: Tests of explanatory hypotheses. Current Anthropology, 26, 223-246.

Kitanishi, K. (1998). Food sharing among the Aka hunter-gatherers in northeastern Congo. African Studies Monographs, 25, 3-32.

Marlowe, F. (1999). Male care and mating effort among Hadza foragers. Behavioral Ecology and Sociobiology, 46, 57-64.

Marlowe, F. (2003). A critical period for provisioning by Hadza men: Implications for pair bonding. Evolution and Human Behavior, 24, 217-229. 
Marlowe, F. (2004a) Mate preferences among Hadza hunter-gatherers. Human Nature, 15(4).

Marlowe, F. (2004b). Dictators and ultimatums in an egalitarian society of hunter-gatherers, the Hadza of Tanzania. In: J. Henrich, R. Boyd, S. Bowles, H. Gintis, C. Camerer \& E. Fehr (Eds), Foundations of Human Sociality: Economic Experiments and Ethnographic Evidence from Fifteen Small-Scale Societies (pp. 168-193). Oxford: Oxford University Press.

McGrew, W., \& Feistner, T. (1992). Two nonhuman primate models for the evolution of human food sharing: Chimpanzees and Callitrichids. In: J. Barkow, L. Cosmides \& J. Tooby (Eds), The Adapted Mind (pp. 229-243). Oxford: Oxford University Press.

Mitani, J., \& Watts, D. (2000). Why do chimpanzees hunt and share meat? Animal Behaviour, 61, 915-924.

Packer, C., \& Pusey, A. (1997). Divided we fall: Cooperation among lions. Scientific American, 276, 52-59.

Peterson, N. (1993). Demand sharing: Reciprocity and the pressure for generosity among foragers. American Anthropologist, 95, 860-874.

Smith, E., \& Bliege Bird, R. (2000). Turtle hunting and tombstone opening: Public generosity as costly signaling. Evolution and Human Behavior, 21, 245-261.

Solomon, N., \& French, J. (Eds) (1997). Cooperative breeding in mammals. Cambridge: Cambridge University Press.

Trivers, R. (1971). The evolution of reciprocal altruism. Quarterly Review of Biology, 46, 35-57.

Vickery, W., Giraldeau, L., Templeton, J., Kramer, D., \& Chapman, C. (1991). Producers, scroungers, and group foraging. American Naturalist, 137, 847-863.

Winterhalder, B. (1986). Diet choice, risk, and food sharing in a stochastic environment. Journal of Anthropological Archaeology, 5, 369-392.

Winterhalder, B. (1996). Marginal model of tolerated theft. Ethology and Sociobiology, 17, 37-53.

Woodburn, J. (1998). Sharing is not a form of exchange: An analysis of property-sharing in immediate-return hunter-gatherer societies. In: C. Hann (Ed.), Property Relations: Renewing the Anthropological Tradition (pp. 48-63). Cambridge: Cambridge University Press.

Zahavi, A. (1995). Altruism as a handicap: The limitations of kin selection and reciprocity. Journal of Avian Biology, 26, 1-3. 